\title{
Dynamic flight load measurements with MEMS pressure sensors
}

\author{
Christian $\operatorname{Raab}^{1}$ (D) Kai Rohde-Brandenburger ${ }^{2}$
}

Received: 20 January 2021 / Revised: 1 June 2021 / Accepted: 8 July 2021 / Published online: 27 July 2021

(c) The Author(s) 2021

\begin{abstract}
The determination of structural loads plays an important role in the certification process of new aircraft. Strain gauges are usually used to measure and monitor the structural loads encountered during the flight test program. However, a time-consuming wiring and calibration process is required to determine the forces and moments from the measured strains. Sensors based on MEMS provide an alternative way to determine loads from the measured aerodynamic pressure distribution around the structural component. Flight tests were performed with a research glider aircraft to investigate the flight loads determined with the strain based and the pressure based measurement technology. A wing glove equipped with 64 MEMS pressure sensors was developed for measuring the pressure distribution around a selected wing section. The wing shear force determined with both load determination methods were compared to each other. Several flight maneuvers with varying loads were performed during the flight test program. This paper concentrates on the evaluation of dynamic flight maneuvers including Stalls and Pull-Up Push-Over maneuvers. The effects of changes in the aerodynamic flow characteristics during the maneuver could be detected directly with the pressure sensors based on MEMS. Time histories of the measured pressure distributions and the wing shear forces are presented and discussed.
\end{abstract}

Keywords Aerospace $\cdot$ Flight testing $\cdot$ Loads $\cdot$ Strain Gauges $\cdot$ Pressure sensor $\cdot$ MEMS

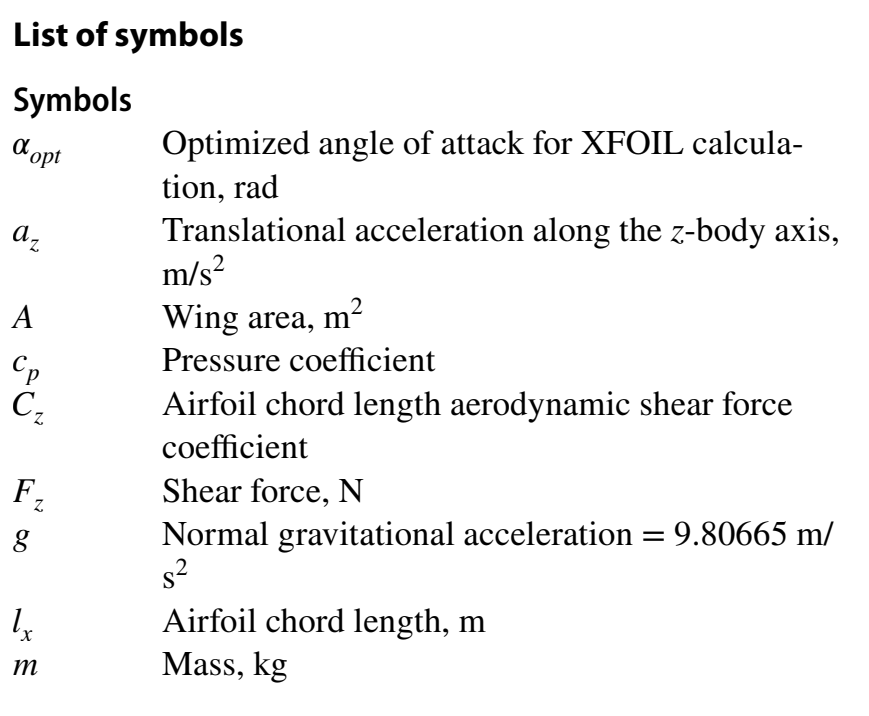

Christian Raab

christian.raab@dlr.de

1 DLR (German Aerospace Center), Institute of Flight Systems, Lilienthalplatz 7, 38108 Braunschweig, Germany

2 DLR (German Aerospace Center), Institute of Aerodynamics and Flow Technology, Lilienthalplatz 7, 38108 Braunschweig, Germany

$\begin{array}{ll}N & \text { Load factor } \\ p & \text { Air pressure, } \mathrm{Pa} \\ p_{0} & \text { Free flow pressure, } \mathrm{Pa} \\ p_{d} & \text { Dynamic pressure, } \mathrm{Pa} \\ p_{s} & \text { Static pressure, } \mathrm{Pa} \\ R & \text { Correlation coefficient } \\ \rho & \text { Air density, } \mathrm{kg} / \mathrm{m}^{3} \\ \mathrm{SE} & \text { Standard error } \\ \sigma_{s} & \text { Standard deviation } \\ V_{0} & \text { Free flow airspeed, } \mathrm{m} / \mathrm{s} \\ V_{I A S} & \text { Indicated airspeed, } \mathrm{m} / \mathrm{s} \\ \Phi, \Theta & \text { Roll angle, pitch angle, } \mathrm{rad}\end{array}$

\section{Subscripts}

avg Averaged value

CG Center of gravity

LH, RH Left hand, right hand

lo Lower airfoil surface

$\mathrm{m} \quad$ Measured value

MEMS MEMS sensor

NB Nose boom

local Local measurement

cor Corrected measurement

ref Reference value

SG Strain gauge 


$\begin{array}{ll}\text { total } & \text { Total value } \\ \text { up } & \text { Upper airfoil surface } \\ \text { W1 } & \text { Wing load station No. 1 } \\ x_{c} & \begin{array}{l}\text { Position along the normalized airfoil chord } \\ \text { length }\end{array} \\ x, y, z & \begin{array}{l}\text { Axes in the geometric reference coordinate } \\ \text { system }\end{array}\end{array}$

\section{Introduction}

Aircraft components like wing, tail, fuselage and stabilizer are designed to withstand the forces and moments occurring during flight maneuvers in the designed flight envelope. Simulations with structural models are used to calculate the loads acting on each component. Validation of these structural models with flight test data is required to successfully satisfy the certification criteria. For this reason, a flight test program is performed with various maneuvers, resulting in loads on the aircraft structure which should be in the admissible operating enveloped. It must be demonstrated to the authorities that the design calculations are reliable and that the specified limits for the occurring forces and moments are not exceeded. The load model developed during the aircraft certification is also important for later operational life. This concerns e.g. the evaluation of structural modifications as well as models for developing individual maintenance plans based on the actual usage of the airframe.

\subsection{Measurement of flight loads}

Accurate and reliable measurements of the forces and moments acting on the structure are essential for the development of an aircraft load model. Electrical strain gauges (SG) have been used for the measurement of aircraft structural loads since more than 70 years [7, 14]. They are available in various configurations with an optimal design for a specific load case, like e.g. shear force, bending and torsion moment. Strain caused by temperature changes is usually compensated by connecting four individual gauges to a full-bridge configuration. An extensive calibration process is necessary, in order to determine the shear force, torsion or bending moment from the measured local strains. Typically, the aircraft structure is divided into several load sections being instrumented with different SG configurations. For the calibration of the SG system different known loads are applied to the aircraft structure with e.g. weights or hydraulic plungers. Using regression techniques, load equations are determined from the relation between the known loads and the measured strains. With these load equations the shear force, torsion and bending moment can be calculated from the strain measured by the SGs for each load section $[3,6]$.
Although the SG measurement technique is a well proven reliable method for the determination of loads, it has a number of disadvantages:

- Electrical wiring has to be installed inside the aircraft structure.

- They have to be attached to the aircraft structure in places which are difficult to access.

- Soldering is needed to join the SG to a circuit and connect them to a power source, a process which is time consuming and prone to errors.

In recent years optical fibers with bragg gratings (FBG) were investigated as a replacement for elaborated SG arrangements $[8,9]$. A single optical fiber may contain hundreds of FBGs being used as strain sensors. This significantly reduces the installation effort and the need for electrical connections. However, like in the case of the conventional SG system, an extensive calibration process is needed in order to determine the loads from the measured strain. Such a calibration process may take several weeks, where the aircraft is jacked up in a hangar and may not be used for other testing purposes.

Another way to determine the aerodynamic loads acting on the structure is the measurement of the surface pressure on the aircraft component. Integration of the pressure distribution over the component surface allows to derive the occurring aerodynamic forces and moments. The measurement of pressure distributions i.e. flow conditions is first of all of interest for the aerodynamic performance. Therefore measurement techniques originally have been developed for the determination of flow conditions around wind tunnel models. Usually the surface pressure is measured by a pressure transducer connected to a small hole in the component surface by a flexible tube. To acquire the pressure distribution e.g. around a wing, several holes and tubes along the wing chord are necessary. For wind tunnel models, space for the tubing can be designed into the structure and the pressure transducers can be placed outside of the model. In case of in-flight measurements on real aircraft many problems may occur with the installation of flexible tubing and pressure transducers:

- Sometimes drilling holes into the original wing structure is not desired or possible. To still establish a smooth surface, the pressure tubes have to be covered under a sealed structure along the wing chord, forming a so called pressure belt with measurement holes in the surface.

- The pressure transducers have to be stored in a separate space inside the aircraft structure.

- The long tubes between the surface hole and the pressure transducer are causing a viscous lag, reducing the dynamic range of the measurement system. 
- To synchronize the individual pressure measurements, the exact length of the tubes has to determined after the installation, if non-static measurements are needed.

The characteristics of the pressure tubing system mentioned above, lead to a time-consuming effort for the installation and calibration of the measurement system. For an in-flight instrumentation setup, the test aircraft has to stay in the hangar for several weeks.

Pressure sensors based on Mirco-Electro-MechanicalSystems (MEMS) have features which may significantly reduce the time and cost for the installation:

- The sensors are only a few millimeters in size, minimizing the installation space and flow disturbances.

- The local absolute pressure is directly measured by the sensors without tubing and viscous lag.

- Large sensor arrays may be formed by integrating several individual sensors on flexible electrical circuits.

- In addition to pressure measurements, the sensor measures its inside temperature which is used for error compensation. This is needed for repeatable and accurate sensor measurements, due to internal heating and its influence to the pressure measurement.

These characteristics of MEMS sensors make them superior to measurement techniques using SGs and pressure tubes in terms of installation effort.

To reduce the aircraft downtime during the certification test program, MEMS sensor technology became interesting for the flight test community. One of the first pressure belt systems built with MEMS was developed by Boeing and the sensor company Endevco in 2001 [15]. It consisted of several chip modules which were equipped with a MEMS pressure sensor and a controller unit for data acquisition. The system flew on the Boeing 757-300, 737-BBJ, 767-400 and on an F-18E aircraft and were successfully applied on a load survey during the certification of the Boeing 787 [11, 16]. Airbus developed their own pressure belt system, which was successfully used during the flight test of the A350 and the A330-NEO aircraft and lead to "less data analysis and fewer flights" [4].

\subsection{Focus of study: dynamic maneuvers}

Even though in recent years the MEMS sensor technology has been used in practice in the flight test community, a direct comparison between the strain-based and the pressure-based method for the determination of flight loads can only be found rarely in the literature. The DLR Institute of Flight System was involved in several Airbus certification flight test programs with its expertise on flight test data analysis. During a joint project, the idea to investigate both measurement technologies for the in-flight determination of loads was born. For this investigation a flight test program was performed with the DLR research aircraft Discus-2c shown in Fig. 1.

The glider is equipped with a load measurement system based on SGs, which were installed during the construction. For the measurement of the pressure distribution around the aircraft wing, a wing glove was constructed and equipped with MEMS pressure sensors by the DLR Institute of Aerodynamic and Flow Technology. A total of 64 commercial of-the-shelf MEMS pressure sensors were integrated on flexible circuit strips and placed inside the wing glove. Equipped with this instrumented wing glove, it was possible to measure the pressure distribution in-flight on one section of the wing. The flight test program included flight test maneuvers with static loads as well as maneuvers where the load was dynamically changing. A first evaluation of the static flight test maneuvers, trimmed horizontal flight and steady turns, showed that the shear forces measured by the SG and the pressured based measuring system were in good accordance [13]. A second phase of the evaluation of the experimental data dealt with the dynamic flight maneuvers e.g. stalls.

Dynamic loads are a complex process, since during the flight maneuver the aerodynamic forces and the flexible structure can interact with each other. Concerning a pressure-based measuring system there are two areas of interest: The first one concerns the aerodynamic process, because e.g. the point of flow separation is of interest for the aerodynamic performance. The second one concerns the forces and moments resulting from changes in the pressure distribution around the aircraft component.

Despite the disadvantages associated with the installation and calibration process, strain gauges have the advantage that they may acquire dynamic load in the range of several hundred $\mathrm{kHz}$, depending upon the data acquisitions system. A pressure measurement system consisting of tubes and pressure transducer may also provide measurements with a rate of hundred $\mathrm{kHz}$. However, because of the viscous lag

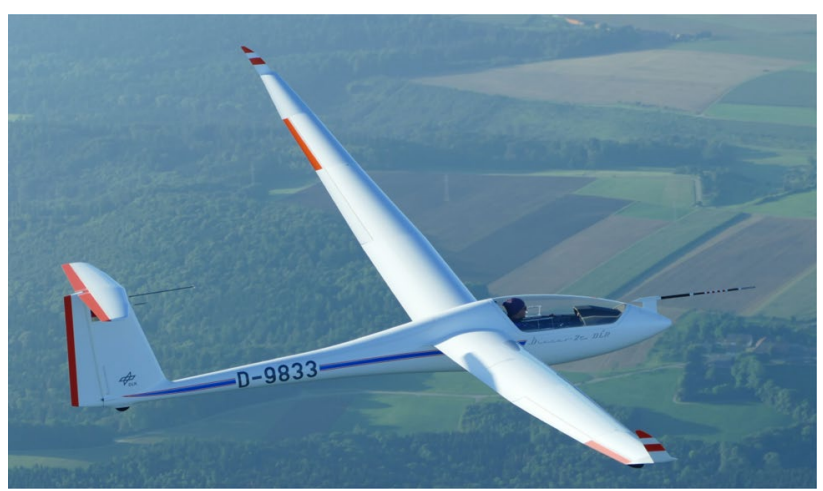

Fig. 1 The DLR Discus-2c research glider 
the dynamic range depends on the actual length of the tubes. In reference [17] laboratory and flight tests were conducted, to evaluate the effects of pressure measurements with different tubing length and diameter and the influence of air density. For unsteady measurements significant errors in amplitude and phase had to be corrected because the tubing behaved like a second order dynamic system. Damping and natural frequency depend on the tubing length and diameter. The results of [17] show, that e.g. for a tubing length of $1 \mathrm{~m}$ significant error corrections are necessary for any measurement rate greater than $10 \mathrm{~Hz}$. The allowable sample rate is further reduced as the tubing length increases. Removing the tubing length or cavity leads to a significant increase in the natural frequencies, however frictional damping and time lag nearly disappear. The authors of [17] mention, if the natural frequencies of the system are too high, amplification from the boundary layer may cause big errors due to high amplification rates at higher frequencies. The cavities in this study had a volume of $30 \mathrm{~mm}^{3}$ for each sensor, resulting in natural frequencies above $1 \mathrm{kHz}$ and no damping.

In the following section the experimental setup, the wing glove design and the performed test maneuvers are presented. Section 3 gives an overview of the data analysis process and explains how the wing shear forces were derived form the SG and MEMS pressure sensor measurements. The pressure distributions acquired during different dynamic maneuvers are presented and discussed in Sect. 4. This includes also a comparison of the shear forces measured by both load measurement methodologies. Final conclusions on the applicability of MEMS pressure sensors for the measurement of dynamic loads and an outlook on future research activities is given in Sect. 5.

\section{Experimental setup}

\subsection{Test aircraft and instrumentation}

Built-in carbon fiber composite, the Discus-2c is a modern glider aircraft built and modified for the DLR by the German manufacturer Schempp-Hirth. Table 1 presents the main technical details of the aircraft as well as its flight envelope limits.

A total of 46 four-active-arm SGs were installed inside the aircraft wing, rear fuselage and the horizontal tail. Calibration of the SGs was performed by a conventional process, applying different specific loads on dedicated points [12]. Equations for dedicated load stations of the aircraft structure were determined and used to calculate the shear force, bending and torsion moment from the measured strains. The whole calibration process lasted nearly 3 weeks with the aircraft jacked up in the hangar. Each side of the aircraft wing has three load stations, distributed along the total wing span.
Table 1 Technical data for the glider aircraft Discus-2c

\begin{tabular}{ll}
\hline Wing span & $18.00 \mathrm{~m}$ \\
Wing area & $11.39 \mathrm{~m}^{2}$ \\
Aspect ratio & 28.50 \\
Mean aero. chord & $0.685 \mathrm{~m}$ \\
Empty weight & $280 \mathrm{~kg}$ \\
Gross weight & $455 \mathrm{~kg}$ \\
Maneuvering speed $\mathrm{V}_{\mathrm{A}}$ & $190 \mathrm{~km} / \mathrm{h}$ \\
Permitted load factor & \\
limits at $\mathrm{V}_{\mathrm{A}}$ & $-2.65 /+5.30 \mathrm{~g}$ \\
Max. Speed $\mathrm{V}_{\mathrm{NE}}$ & $280 \mathrm{~km} / \mathrm{h}$ \\
Stall Speed & $75 \mathrm{~km} / \mathrm{h}$ \\
Wing glove airfoil & \\
chord length $l_{c}$ & $0.902 \mathrm{~m}$ \\
Wing part area $A_{r e f, W 1}$ & $5.141 \mathrm{~m}$ \\
\hline
\end{tabular}

For the investigation of the load measurement techniques, however only the shear force measured at load station No. 1 on the RH wing side was considered, depicted in Fig. 2.

This load station is close to wing root and near the position of the wing glove, containing the MEMS pressure sensors. The shear force calculated with the load equations from the measured strain was validated with check loads during the calibration. For the shear force measured at the RH wing station a maximum relative error of $3.6 \%$ was determined during this validation process [12].

To investigate the loads occurring during the dedicated flight maneuvers, the Discus-2c research glider was equipped with additional instrumentation as presented in Fig. 2. Static and total pressure as well as the angle of attack (AoA) and the angle of sideslip (AoS) were measured with pressure transducers located in a 5-hole probe at the front of the aircraft. A probe situated at the RH side of the cockpit cover measured the total air temperature (TAT). The attitude angles, translational accelerations and gyroscopic rates were measured with an inertial measurement unit (IMU) located in the equipment bay. A GPS receiver with two antennas located at the aircraft nose and in the mid-fuselage allowed a precise determination of the aircraft heading and provided position updates for the stabilization of the IMU measurements. The time signal from the GPS receiver was also used for the synchronization of all sensor measurements. Laser distance sensors installed at the steering rods close to each control surface measured the position of aileron, elevator and rudder.

A central data acquisition system installed in the equipment bay recorded the sensor measurements with a sample rate of $100 \mathrm{~Hz}$. This included also the measurements of the SGs and the 64 MEMS sensors installed in the wing glove. After each flight the data was downloaded and processed to a MATLAB file for further data analysis. 


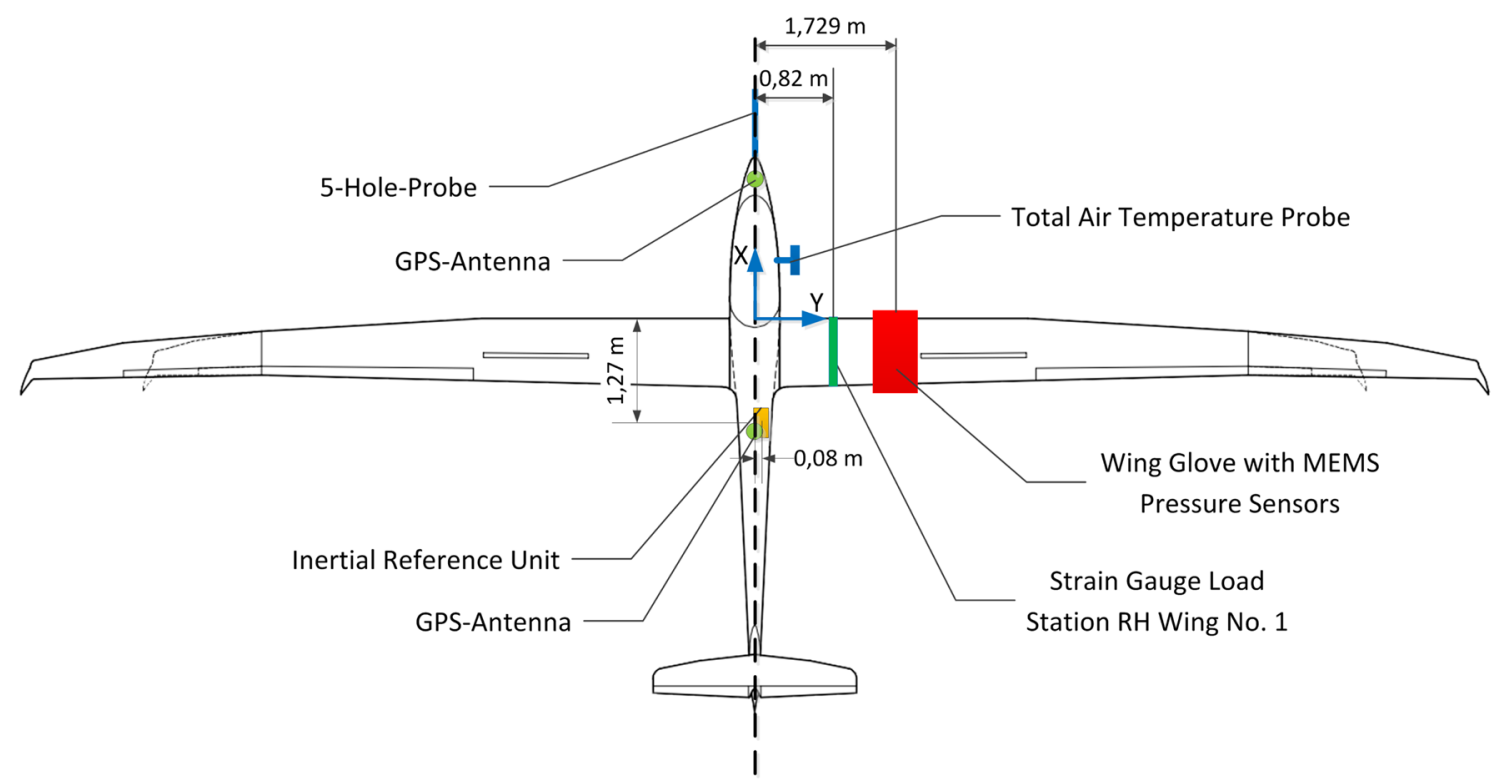

Fig. 2 Flight test instrumentation of the Discus-2c

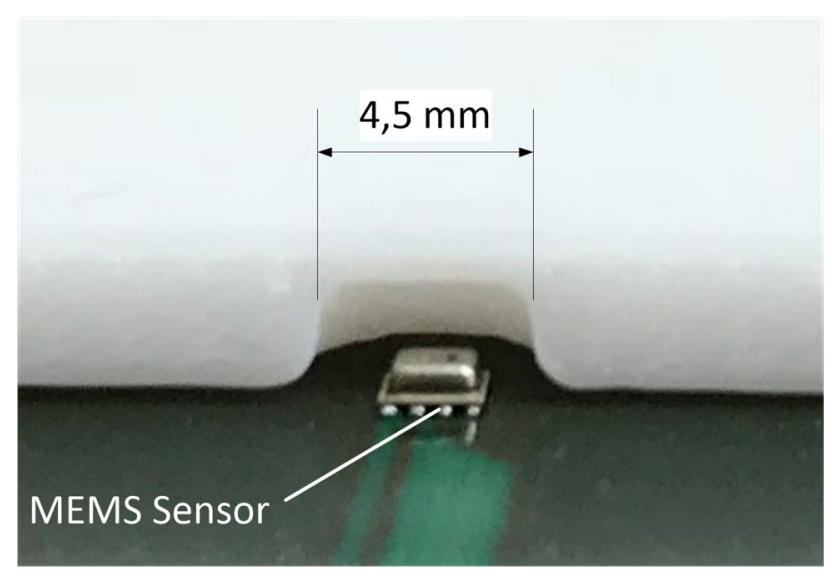

Fig. 3 MEMS pressure sensor in the 3D-printed cavity structure

\subsection{MEMS pressure sensor}

The pressure sensors used in this test were BMP280 [1], manufactured by Bosch with a size of $2 \mathrm{~mm} \times 2.5 \mathrm{~mm}$. Figure 3 shows an example of a MEMS sensor integrated in the cavity structure of the wing glove.

The BMP280 is an absolute barometric pressure sensor, based on a small piezo-resistive membrane. Data communication can be established with the onboard SPI/I ${ }^{2} \mathrm{C}$ logicinterface. For the calibration of the pressure measurements, the local sensor temperature is measured onboard. The corrected pressure measurement can be determined from the raw temperature and pressure measurements, using a polynomial function described in [1]. Instead of using a common set of factory parameters for this functions, individual parameters were determined for each MEMS sensor using an own calibration process. All pressure sensors were placed in a climate chamber, and different pressure and temperature combinations were tested with a calibrated pressure gauge. This resulted in different calibration factors for each sensor, optimized for the expected measurement envelope. The absolute accuracy of the sensors could be increased significantly from $1 \mathrm{hPa}$ to under $20 \mathrm{~Pa}$. The influence of acceleration was tested on a rotor test rig as well and showed no influence up to $8 \mathrm{~g}$ in all axes.

Printed circuit boards (PCBs) were designed with 16 sensors each, two PCBs were read out by one control box. The control boxes managed the sensor raw data, performed the pressure calculations and sent the data to the data acquisition system at a rate of $100 \mathrm{~Hz}$.

\subsection{Wing glove}

The Discus-2c is primarily used as a reference for surveying the flight performance of other gliders. To prevent the aerodynamic shape of this reference glider, a wing glove, depicted in Fig. 4 was designed, which could be shoved onto the inner wing by unmounting the outer wing with the winglet.

The structure of the wing glove is presented in Fig. 5.

It was designed as a 3D-printed construction, reinforced with aluminum rips and an outer layer of glass fiber reinforced plastic, coated with paint. Inside the 3D-printed parts, slots for four PCBs and the cables were designed. Measurement holes of $0.3 \mathrm{~mm}$ diameter, were drilled rectangular to 


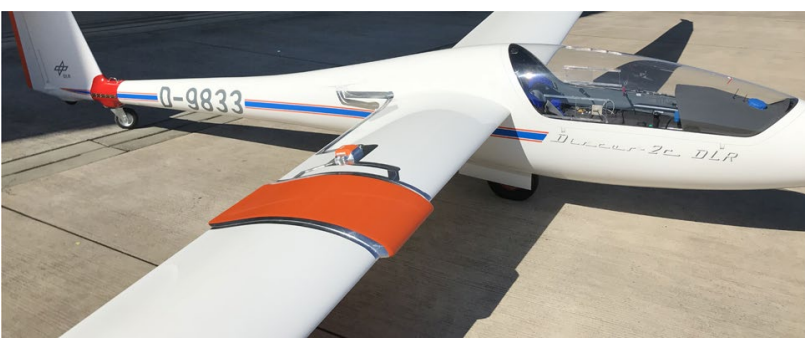

Fig. 4 The wing glove mounted on the wing of the Discus-2c for flight test

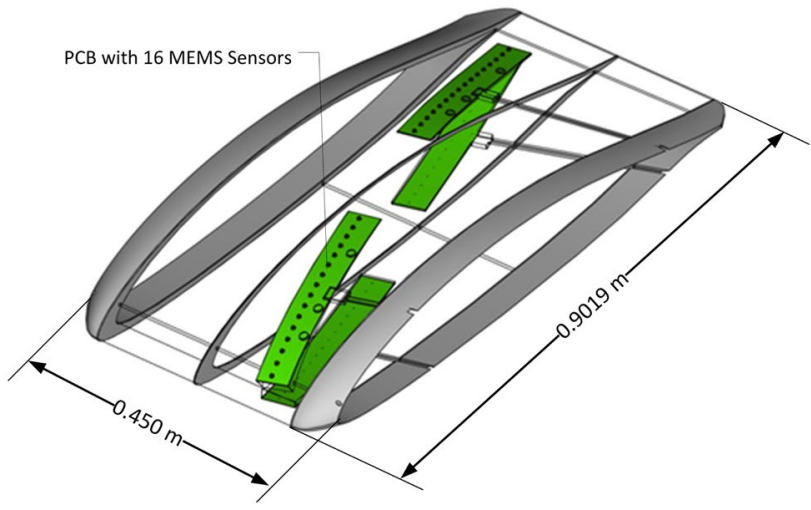

Fig. 5 Wing glove structure with position of the PCBs

the surface into the designated cavities for each pressure sensor. After the drilling, the PCBs and the cables were glued in and each pressure sensor was tested. Unfortunately due to a leaking print structure, nine of the 64 MEMS sensors showed corrupted measurements which were discarded during the data analysis process.

The airfoil geometry at the mounting position was precisely measured, so that the wing glove could be slid to the position and fixed on the wing with tape without any big gaps. The wing glove shape was equivalent to the airfoil at the respective wing position. However, to provide enough space for the sensor housing, the wing glove is around $10 \%$ greater in cross section size. After the test flights, the airfoil of the mounted wing glove was measured again with a 3D-scanner, to identify eventual changes due to mounting and to verify the position of each sensor cavity. A repeated calibration test of the MEMS sensors showed no significant changes in measurement accuracy.

\subsection{Dynamic test maneuvers}

For the investigation and comparison of the flight load determination methods based on strain and based on pressure measurements, it was important to perform maneuvers with different variations of the aerodynamic forces and moments acting on the aircraft wing. The main part of the test program consisted of steady maneuvers, such as trimmed wings-level horizontal flights and steady turn maneuvers with different bank angles. These were used for the investigation of steady load conditions presented [13]. All maneuvers were performed at different initial speeds of $100,120,160 \mathrm{~km} / \mathrm{h}$.

Another part of the test program were maneuvers with dynamically changing loads and unsteady aerodynamic characteristics. Load changes with an $N_{z}<1 \mathrm{~g}$ could be established with a Pull-Up Push-Over maneuver. Starting from a wings level condition the pilot applied a step input to the elevator in nose-up direction. After 2 seconds he applied a step input on the elevator in the nose down direction to achieve a constant vertical load factor. At a pitch angle of $-25^{\circ}$ the pilot applied again a nose-up elevator input with constant load factor to return the aircraft to a stabilized horizontal flight condition. This maneuver was also performed as a Push-Over Pull-Up, starting with a nose-down elevator input. Both flight maneuvers were performed with different initial $V_{I A S}$ similar to the steady maneuvers.

To extend the time span with a condition of vertical loads smaller than $1 \mathrm{~g}$, a parabolic flight maneuver was performed. In this case the pilot started from a wings level flight condition at $V_{I A S}=160 \mathrm{~km} / \mathrm{h}$ and performed a nose-down elevator input to gain speed. At $-25^{\circ}$ pitch attitude he initiated a nose up elevator input reaching a point with the maximum vertical load factor. After reaching a pitch attitude at around $+25^{\circ}$, he started again a nose-down elevator input and tried to maintain a constant near zero vertical load factor. The aircraft was recovered again to a wings-level horizontal flight condition.

Stall maneuvers were also an important part of the flight test program, because these were of interest for the investigation of unsteady flow conditions. Starting from a trimmed wings-level flight condition at $V_{I A S}=100 \mathrm{~km} / \mathrm{h}$ the pilot performed a smooth nose up elevator input. A deceleration of $1 \mathrm{~km} / \mathrm{h}$ per second was targeted while maintaining a wingslevel condition. At the point of full stick aft condition and flow separation i.e. stall, the aircraft was recovered again to a horizontal flight condition. During the stall maneuver, the vertical load factor remained almost constant at $N_{z}=1 \mathrm{~g}$, while the point of flow separation moves towards the airfoil leading edge. At the stall condition, the load factor suddenly drops to nearly $0.4 \mathrm{~g}$. Capturing this effect of unsteady aerodynamic conditions was of interest for the evaluation of the MEMS sensor technology.

A detailed summary of the total flight test program can be found in [13]. It should be mentioned that a maximum load factor of $+4 \mathrm{~g}$ and a minimum load factor of $-0.4 \mathrm{~g}$ was achieved with the test maneuvers. This indicated that a good coverage of various vertical loads were achieved with the designed flight test program. 


\section{Methodology}

\subsection{Data preparation}

The sensor measurements collected during the flight test program were segmented into different maneuver time slices. A data compatibility check (DCC) was performed on the air data and IMU measurements [5]. Results of the DCC were used to identify errors or malfunctions in the aircraft sensors. If necessary, models for the correction of the sensor measurements were identified. Before each flight a reference condition was established, where the aircraft was leveled on ground with $\theta=\phi=0^{\circ}$ in a standstill position. Pressure measurements recorded during this condition were used to identify and correct offsets in the static and dynamic pressure sensors of the 5-hole probe as well as the MEMS pressure sensors. The leveled 1 -g condition on ground was also used as a reference for the SG measurements because in this case the structure is only loaded with its own weight. The application of the detected offset is explained in detail in Sect. 3.2.

\subsection{Determination of aerodynamic wing shear forces from SG measurements}

For the comparison of the two load measurement techniques, the shear force $F_{z, W 1}$ caused by aerodynamic loads and measured at the RH wing load station No. 1 was defined as a common benchmark figure. Figure 6 describes the shear force location and its definition. It shows the location of the reference coordinate system, centered at the aircraft plane of symmetry and the wing root.

The aerodynamic shear force can be regarded as point load, acting on the center of lift of the RH wing part and pointing downward in the z-direction. The center of lift changes, however, depending on the wing deformation and the aerodynamic flow conditions. For this reason a simplification has been made in the following considerations: as depicted in Fig. 6, the center of gravity of the RH wing part $C G_{W 1}$ is used as reference point for the measured shear force.

The shear force at the RH load station No. 1 was calculated from the strain measured by the SGs using the load equations from the calibration process [12]. For the determination of the shear force $F_{z, S G, W 1}$, caused only by the aerodynamic lift surface load, depicted in Fig. 6, it is necessary to subtract the inertial and weight forces from the measured

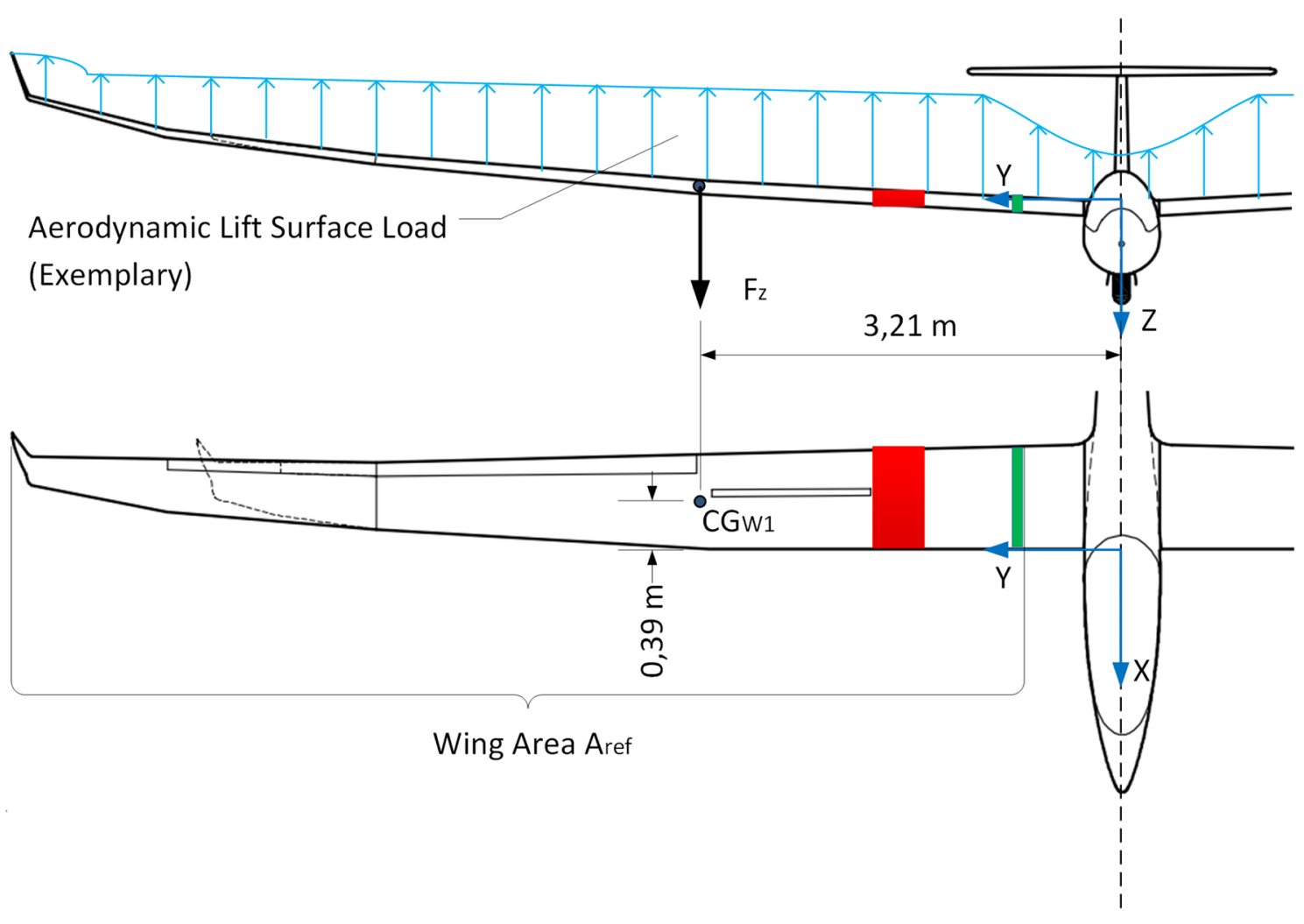

Fig. 6 Definition and location of the RH wing aerodynamic shear force 
one. This calculation was performed by applying the following equation:

$$
\begin{aligned}
F_{z, S G, W 1}= & \underbrace{F_{z, S G, W 1, m}}_{\text {SG Measurement }}-\underbrace{F_{z, S G, W 1, r e f}}_{\text {Weight Force at Ref. Cond. }} \\
& -\underbrace{m_{W 1} \cdot\left(a_{z, C G_{W 1}}+g\right)}_{\text {Inertial Force }}
\end{aligned}
$$

Here $F_{z, S G, W 1}$ is the aerodynamic shear force determined with the SGs, $F_{z, S G, W 1, m}$ is the actual SG measurement, $F_{z, S G, W 1, r e f}$ the measured weight force at the standstill reference condition. The last term of the equation is the inertial force calculated from the wing part mass $m_{W 1}$ and the acceleration $a_{z, C G_{W 1}}$ at the position of the wing part CG. The acceleration $a_{z, C G_{W 1}}$ was calculated from the IMU measurements and the relative position between the wing part CG and the IMU location. The normal acceleration is added, because the IMU measurement already contains a $1 \mathrm{~g}$ earth acceleration component but with a negative sign.

\subsection{Determination of aerodynamic wing shear forces from pressure distributions}

Each MEMS sensor integrated in the wing glove measures the local absolute air pressure on the surface. The aerodynamic shear force for the RH wing part is determined from the pressure distribution of the upper and lower wing glove surface. For each MEMS sensor the local dimensionless pressure coefficient $c_{p}$ was calculated with the following equation:

$c_{p}=\frac{p_{\text {local }}-p_{0}}{\frac{1}{2} \rho V_{0}^{2}}=\frac{p_{M E M S, m}}{p_{d, N B, c o r}}-\frac{p_{s, N B, c o r}}{p_{d, N B, c o r}}$,

where $p_{M E M S, m}$ is the pressure measurement of the individual MEMS sensor at the corresponding location on the wing glove, $p_{s, N B, c o r}$ is the static and $p_{d, N B, c o r}$ is the dynamic air pressure measured with the 5-hole probe. In a next step, the dimensionless shear force coefficient $C_{z}$ was determined by integrating the difference between the upper and lower pressure distribution over the normalized airfoil length $x_{c}$ according to Eq. 3 .

$C_{z}=\int_{0}^{1} c_{p, u p}\left(\mathrm{~d} x_{c}\right)-c_{p, l o}\left(\mathrm{~d} x_{c}\right) \mathrm{d} x_{c}$

The shear force $F_{z, M E M S, W 1}$ acting on the RH wing part for the corresponding load section No. 1 was calculated with Eq. 4 from the dynamic pressure $p_{d, N B, c o r}$, the dimensionless shear force coefficient $C_{z}$ and the reference area for the corresponding wing part $A_{\text {ref }, W 1}$ :
$F_{z, M E M S, W 1}=p_{d, N B, c o r} \cdot C_{z} \cdot A_{r e f, W 1}$

The reference area used in Eq. 4 was estimated from the wing geometry data and considers only the $\mathrm{RH}$ wing part for load station No. 1 as shown in Fig. 6. It is listed in Table 1 and considers only the wing area where the SG load station was calibrated for. The calculation of the shear force with Eq. 4 assumes that the local coefficient $C_{z}$ and the measured pressure distribution is constant along the wing part. This is a simplification neglecting changes in the airfoil shape and the Reynolds number as well as local effects of flexibility and unsteady aerodynamics.

Prerequisite for an exact calculation of the shear force is a determination of the pressure curves on the upper and lower side of the airfoil as accurately as possible from the individual MEMS pressure measurements. Due to the limited number of MEMS sensors and available installation space in the wing glove, it was not possible to distribute the sensors equally along the airfoil. No sensors were available in the middle and the trailing edge of the airfoil. This was aggravated by the fact that some sensors in the rear area showed corrupted measurements during an installation check. For this reason, a data processing method was developed to handle and mitigate the effects of missing pressure information.

An example for the pressure distributions determined from the MEMS measurements for a trimmed wings-level flight maneuver is shown in Fig. 7.

The pressure coefficients calculated for each MEMS sensor with Eq. 2 were averaged over the steady time section of the maneuver. They are shown in the diagram for the respective upper and lower wing glove surface as black and white triangles. For each pressure coefficient derived from the MEMS measurements the standard deviation is presented as an error bar around the triangle. In the presented example analysis of a steady maneuver of $18 \mathrm{~s}$, the error bars corresponded to a variation of nearly $\pm 50 \mathrm{~Pa}$ in the MEMS measurements. The pressure distribution for the upper and lower wing glove surface was calculated in a step-by-step procedure:

1. The aerodynamic flow analysis program XFOIL [2] was used to generate supporting points in areas not covered by measurements. The standard XFOIL setup was used with the wing glove airfoil geometry and the Reynolds number was calculated from the measured data. Using a linear regression method, the XFOIL pressure distribution was adapted to the MEMS pressure measurements with the airfoil angle of attack $\alpha_{\text {opt }}$ as optimizing input parameter. The local AoA at the wing glove position differs from the AoA measured with the nose boom because of downwash effects of the three-dimensional wing and influences of the fuselage [10]. For this reason, a correction by determining the $\alpha_{\text {opt }}$ for the XFOIl 
Fig. 7 Pressure distributions determined from MEMS measurements and an optimized XFOIL model calculation for a trimmed wings-level flight condition

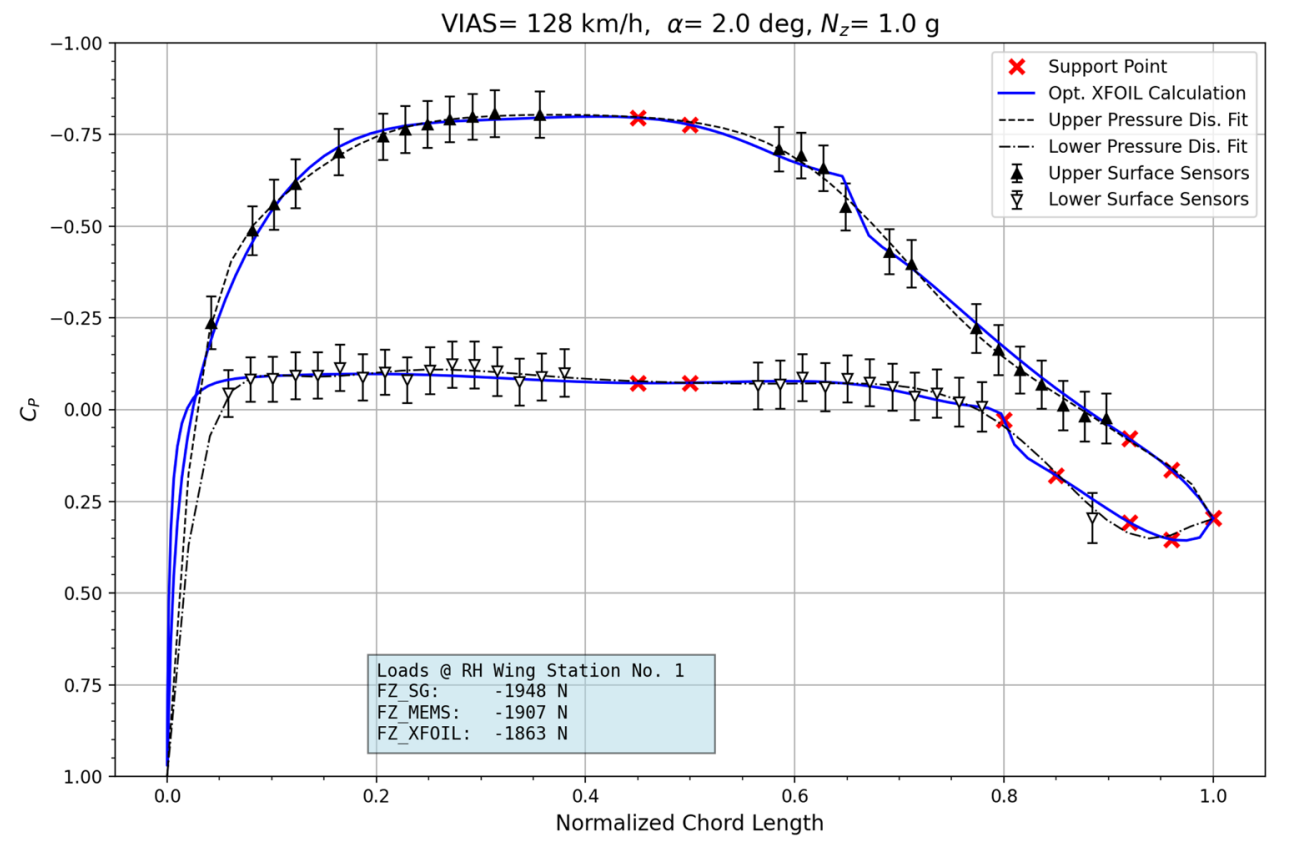

calculation was necessary. Even if the input parameter $\alpha_{\text {opt }}$ was optimized, XFOIL can hardly predict pressure distributions at high AoA with separated flow. In Fig. 7 the optimized pressure distribution by XFOIL is represented by a solid blue line. The supporting points are indicated by red crosses in the mid and rear parts of the airfoil.

2. The MEMS pressure measurements, the supporting points and a stagnation point at the airfoil leading edge were used in a polynomial fitting method of the 12th order for the generation of the surface pressure distributions. Figure 7 shows the results of this fitting method as black dashed line for the upper and as black dashed dotted line for the lower airfoil surface.

Equations 3 and 4 were applied to the pressure distributions. The results for the calculated shear forces using the polynomial fitting method (FZ_MEMS) and the optimized XFOIL model calculation (FZ_XFOIL) are shown in the blue box of the figure. It contains also the shear force measured by the SGs being calculated with Eq. 1 .

More details about the calculation of the pressure distributions and a comparison of both methods can be found in [13]. For the analysis of steady load conditions like the trimmed horizontal flight and the constant turn maneuvers, the data processing method was performed on the total averaged measurements of one maneuver time slice. Depending on the duration of the steady conditions, the maneuver time slice had a duration of 5 to $20 \mathrm{~s}$ with a sampling rate of $100 \mathrm{~Hz}$. However, for the analysis of the dynamic flight maneuvers the measurements were averaged to data points of $20 \mathrm{~Hz}$. For each data point, the step-by-step calculation process as described was performed.

The evaluation of the shear force based on the optimized XFOIL calculation was not considered for the analysis of the dynamic flight maneuvers, because the model is not able to reproduce realistic aerodynamic flow conditions during high angles of attack. This leads to high inaccuracies in the calculated pressure distributions especially in the leading edge parts of the airfoil [13]. Unsteady flow conditions like e.g. a beginning flow separation during stall can not be determined accurately. For this reason, the XFOIL model is only used to calculate the supporting points and only the polynomial fitting method is considered for the calculation of the shear force.

\section{Results and discussion}

In the following sections, the results of three dynamic flight maneuvers are presented and discussed. The pressure measurement technology based on MEMS sensors is evaluated under two aspects: First, the comparison between the shear force determined with the pressure measurements and the one determined with the SGs. Second, the aerodynamic characteristics which can be detected with the pressure sensors based on MEMS. For this reason events within the maneuver time histories were selected, where the determined pressure distributions are presented. The first event is the initial condition of the maneuver, the others are selected points with extreme values of AoA or the vertical load factor $N_{z}$. 


\subsection{Pull-up push-over maneuver}

As already explained in Sect. 2, the Pull-Up Push-Over maneuver consists of a dynamic load change caused by an elevator nose up command, followed by a nose down input, when an attitude angle of $25^{\circ}$ is reached. The time series plots in Fig. 8 show the flight data for this flight maneuver.

The first diagram shows the flight velocity $V_{I A S}$, which is followed by line plots for the AoA, the pitch and roll attitude angles, and the vertical load factor $N_{z}$. In the last diagram of the figure, time series plots for the shear forces determined with Eqs. 1 and 4 are shown. Red dashed lines labeled with numbers indicate the events at which plots with the measured pressure distributions were evaluated in more detail. The respective pressure distribution curves are presented in Fig. 9.

In the diagrams, the MEMS pressure measurements for the upper wing glove surface are shown as black triangles and as white triangles for the lower surface. A black dashed and a black dashed-dotted line shows the pressure distribution curve for the respective upper and lower wing glove surface. Both pressure distribution curves were determined with the polynomial fitting method, described in Sect. 3. Red crosses indicate the supporting points determined with the optimized XFOIL model calculation. The error bars around the respective triangles indicated the standard deviation of the averaged measurement values to $20 \mathrm{~Hz}$ and allow an evaluation of the measurement variation. In the blue box the numeric values for the shear force measured by the SGs and the one determined from the MEMS pressure measurements are shown.

Time point No. 1 marks the beginning of the flight maneuver, which is a trimmed wings-level condition with a $V_{I A S}$ of $155 \mathrm{~km} / \mathrm{h}$ and vertical load factor $N_{Z}$ of $1 \mathrm{~g}$. Figure 9 shows a typical pressure distribution for this flight situation. Considering the absolute numeric values, the shear force determined from the MEMS pressure sensors is nearly $100 \mathrm{~N}$ greater than the one measured with the SGs. As the pilot pulls the elevator, the aircraft starts to rotate to a nose up flight attitude. It reaches a point with the maximum AoA of $3^{\circ}$, labeled with the time point No. 2 and a vertical load factor $N_{z}$ of nearly $1.8 \mathrm{~g}$. The respective pressure distribution shows a greater difference in the pressure coefficients between the upper and lower airfoil surface, when compared to the initial situation. In absolute terms, the shear forces are greater than the ones for the trimmed horizontal flight. However, the one measured by the SGs is nearly $240 \mathrm{~N}$ greater than the shear force determined with the MEMS pressure sensors. Having reached the maximum pitch angle, the pilot initializes a nose-down elevator input, resulting in a vertical load factor $N_{z}$ of nearly zero, labeled as event No. 3 . The shear force measured by
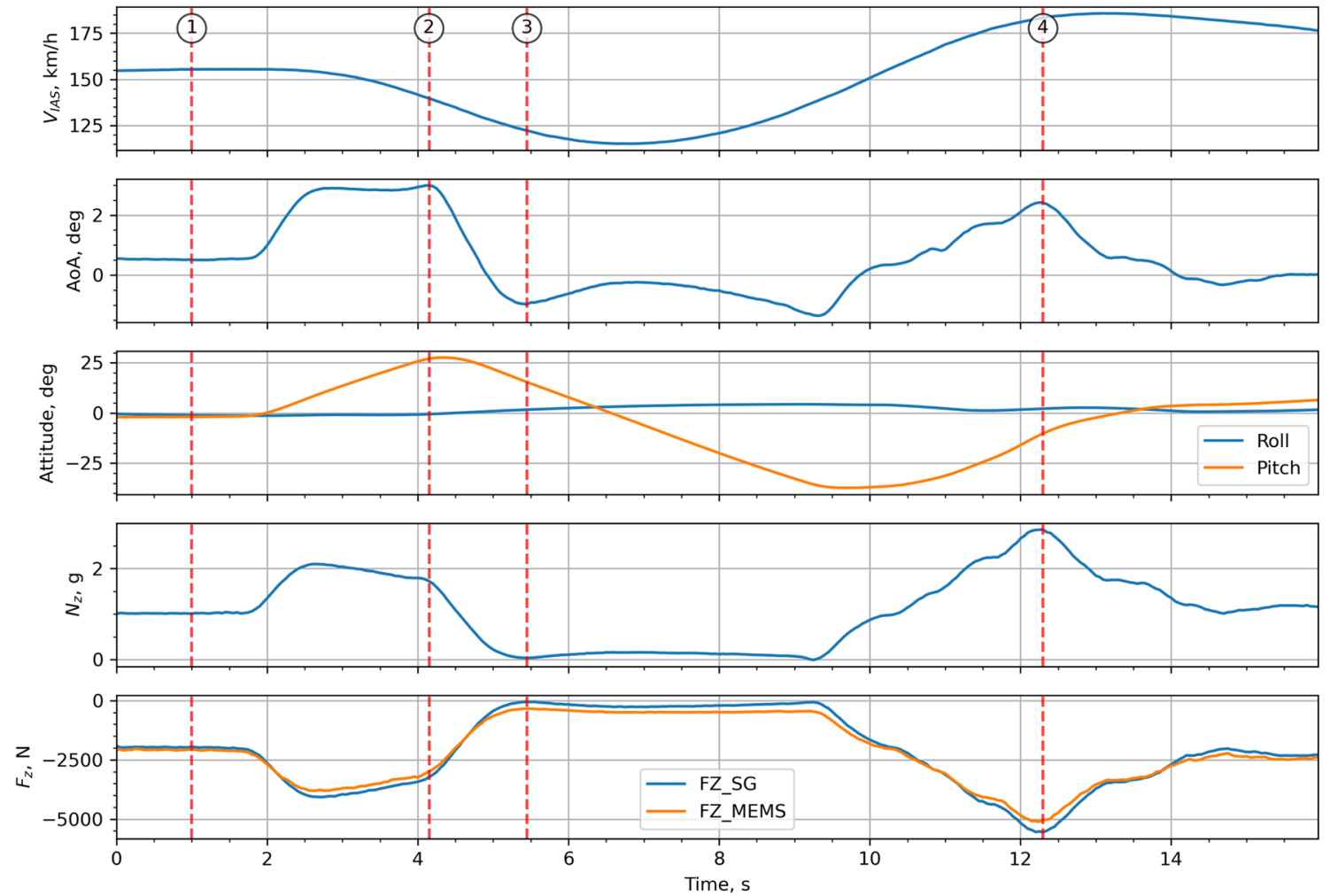

Fig. 8 Flight data measurements from a pull-up push-over maneuver 

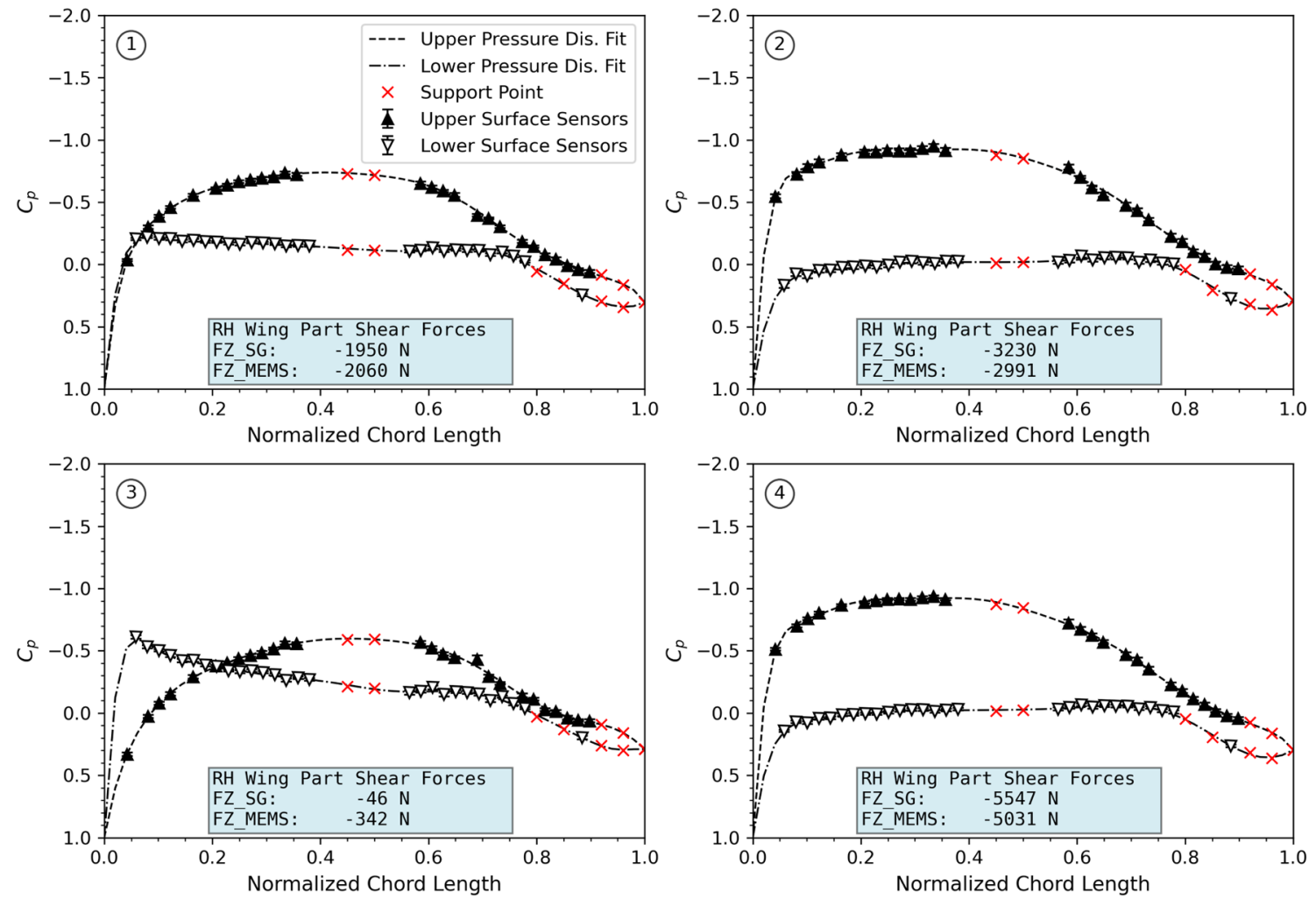

Fig. 9 Pressure distribution curves determined with MEMS pressure sensor measurements for specific points in time during the Pull-Up PushOver maneuver

the SGs is only $-46 \mathrm{~N}$, whereas the one determined with the MEMS is almost $300 \mathrm{~N}$ lower. When compared to the other diagrams, there is a major difference in the pressure distribution for this flight situation. In the area around the leading edge the bottom surface pressure coefficients are lower than the ones for the upper surface. At the normalized chord length of 0.2 this pressure distribution changes again to the opposite side with higher pressure coefficients for the bottom airfoil surface. This pressure distribution is characterized by negative AoA of nearly $-1^{\circ}$. Having reached a nose down pitch attitude angle of nearly $-30^{\circ}$, the aircraft is stabilized again to a horizontal flight condition with a nose-up input to the elevator. Although this is not part of the typical Pull-Up Push-Over maneuver, the event is presented in Fig. 8 as event No. 4, because the maximum vertical load factor $N_{z}$ of nearly $2.5 \mathrm{~g}$ is reached here. The respective pressure distribution is very similar in terms of values and shape to the one shown for time point No. 2, however, the absolute shear forces are much higher. This is caused by a higher flight velocity for time point No. 4, which is nearly $185 \mathrm{~km} / \mathrm{h}$ compared to $140 \mathrm{~km} / \mathrm{h}$ at time point No. 2. There is a difference of more than 500 $\mathrm{N}$ in the shear forces determined by the SGs and the one determined from the MEMS pressure measurements.

\subsection{Parabolic flight maneuver}

The flight data measurements gathered during the Parabolic Flight test maneuver are presented in Fig. 10. Significant events were marked with numbers and the respective pressure distributions can be seen in Fig. 11.

This maneuver is similar to the pull-up push-over concerning the longitudinal motion, it however demonstrates the repeatability of the examined measurement methods. The maneuver starts with a trimmed horizontal flight condition marked with the event No. 1 and a speed of $155 \mathrm{~km} / \mathrm{h} V_{I A S}$, the respective diagram in Fig. 11 shows the typical pressure distribution for this initial $1 \mathrm{~g}$ flight condition. In the following the pilot initializes a nose-down dive, resulting in an increase in airspeed, a vertical load factor $N_{z}$ near zero and a negative AoA. This part of the maneuver is marked with the No. 2 in the flight data plots. In the airfoil leading edge area, the MEMS pressure measurements of the bottom surface show lower pressure coefficients than the ones for the upper surface. At a position of 0.2 normalized chord length the pressure curves swap, having lower pressure coefficients on the upper surface. The flight maneuver continues with a elevator nose-up input, reaching the point with the highest AoA of nearly $4^{\circ}$. This point is labeled with No. 3 

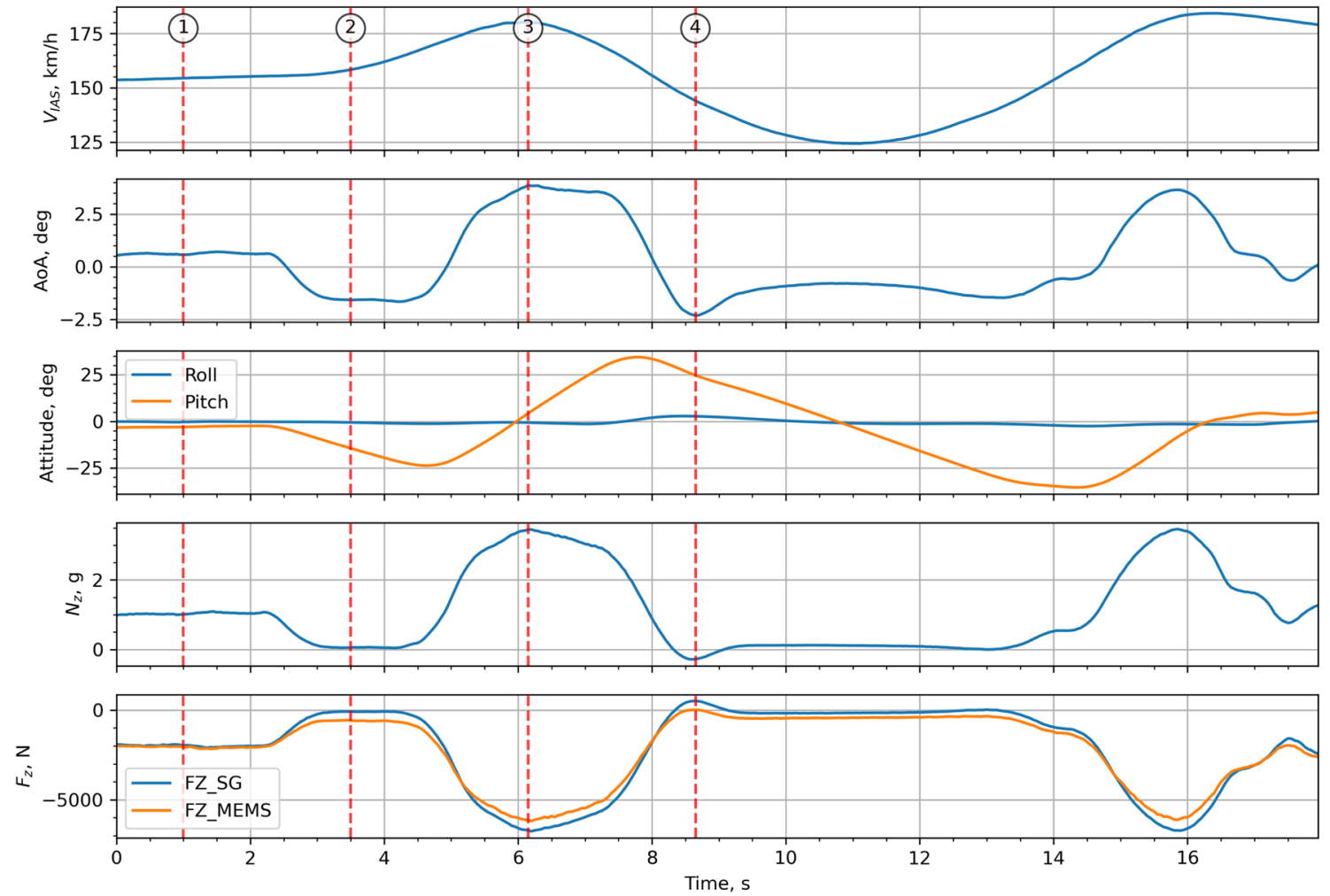

Fig. 10 Flight data measurements from Parabolic Flight test maneuver
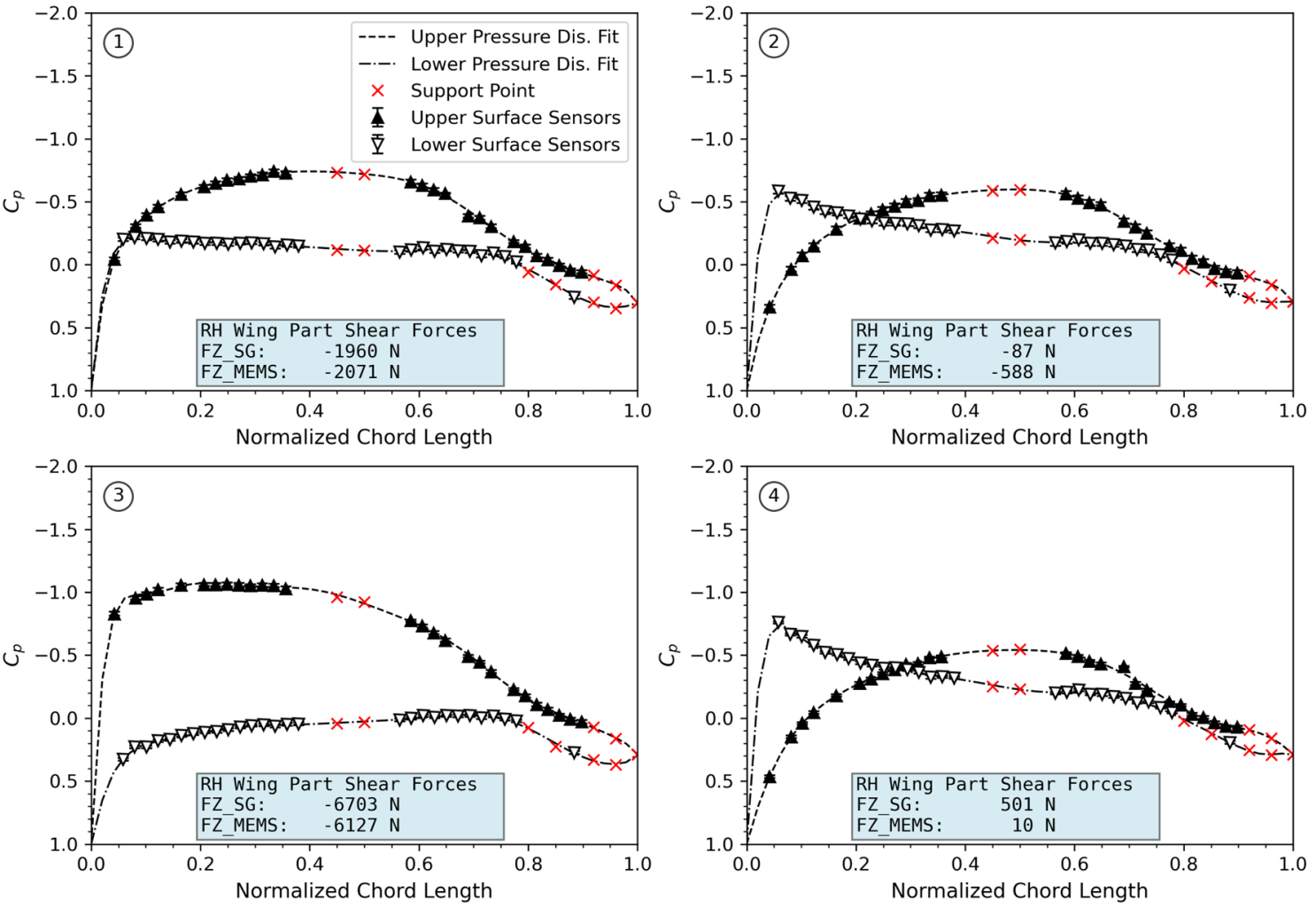

Fig. 11 Pressure distribution curves determined with MEMS pressure sensor measurements for specific points in time during the Parabolic Flight test maneuver 
and features a high vertical load factor of $N_{z}=3.5 \mathrm{~g}$. The respective pressure distribution in Fig. 11 shows are large difference between the pressure coefficients of the upper and lower wing glove surface, indicating a high aerodynamic load. Having reached a $35^{\circ}$ pitch angle, the pilot initializes a nose-down dive, where the vertical load factor becomes negative. This flight situation causes shear forces in the positive direction and is labeled with the event No. 4. The shear forces determined for this maneuver with the SG and from the pressure distributions show differences of similar quantity like in the Pull-Up Push Over maneuver. Their time history plots presented in Fig. 10 show that they have however a corresponding progression.

\subsection{Shear Forces during Maneuvers with Dynamic Load Changes}

The discrepancy between the shear forces for both presented flight maneuvers with dynamic load changes is analyzed in more detail and shown in Fig. 12.

The diagram contains the measured shear force values from the Pull-Up Push-Over and the Parabolic Flight maneuver, marked with red circles for the SG and with blue crosses for the MEMS pressure sensor method. A linear fitting of the data points was performed and is present respectively as red dashed dotted and a blue dashed line plots. In the diagram legend the regression equations for both linear fittings are shown. Both shear force measurements show a nearly linear dependency on the vertical load factor. The shear forces determined from the MEMS pressure measurements however have a larger scattering and a higher standard error than the ones determined with the SGs. This is indicated by standard errors and the $R^{2}$ values, presented near the regression equations. When comparing the regression equations from both load measurement methods, the one based on the MEMS pressure measurements has a significant offset of $-362.6 \mathrm{~N}$, whereas the SGs have an offset of $+17.4 \mathrm{~N}$. The slope of the regression equation for the SGs is steeper than the one for the MEMS pressure sensor technique. This discrepancy in the shear force measurements is mainly caused by the error made by extrapolating the pressure distribution around the wing glove on the total RH wing span. Two effects are neglected with this assumption:

- Wing torsion and bending leads to different local AoAs along the wing span, causing different pressure distributions and local aerodynamic loads.

- Unsteady aerodynamic flow conditions along the wing span, occurring during highly dynamic flight maneuvers, are not captured with a single instrumented wing section.

A mitigation of this extrapolation error would be to increase the number instrumented wing chords along the span. That way the local resolution of the pressure measurements could be increased, capturing local differences in the pressure distributions. Despite the simple test setup used in this study, the shear forces derived from the pressure distributions show a good qualitative agreement with the shear forces determined with the SGs.
Fig. 12 Shear forces determined from the SG and MEMS pressure measurements vs. the vertical load factor for the PullUp Push-Over and the Parabolic Flight maneuver

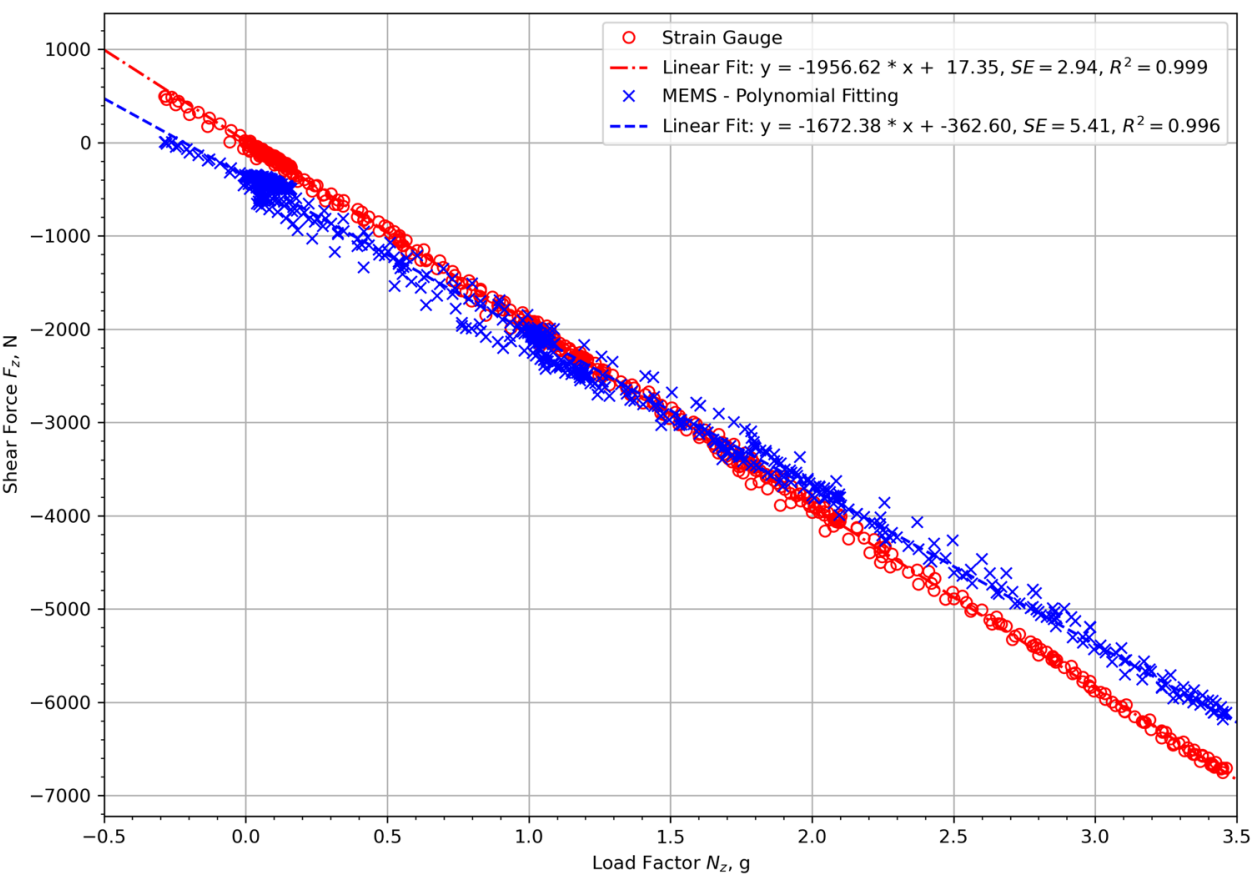




\subsection{Stall}

Stalling the aircraft is a typical flight test maneuver for evaluating the aircraft aerodynamic performance. The Discus-2c has good-natured stall characteristic, even with the stick fully pulled, it remains in a stable gliding condition for a long time. Although the speed is constantly decreasing during the stall maneuver, the vertical load factor remains nearly constant at $1 \mathrm{~g}$ until the point of total flow separation. Figure 13 shows selected flight test parameters for this maneuver, the respective pressure distributions are presented in the diagrams of Fig. 14.

Highlighted with the event No. 1 in the flight data plots, the stall maneuver starts with a trimmed wings-level flight condition and speed of $105 \mathrm{~km} / \mathrm{h} V_{I A S}$. The respective pressure distribution is typical for a 1-g flight condition and very similar for the initial characteristics of the other two presented flight test maneuvers. The AoA increases during the maneuver until the inflow reaches a highly unsteady state, presented in the diagram for event No. 2. The differences in the pressure gradients on the upper and lower wing surface have increased extremely, compared to those in the initial situation. This point is also characterized by the beginning of increasing noise in the measurements of vertical load factor and the wing shear forces. The diagram for the pressure distribution around the airfoil shows the typical signs for the beginning of flow separation at the wing trailing edge:

- The pressure curve on the upper side shows a steep pressure change, starting with a value of -2.5 near the leading edge to almost zero at the trailing edge.

- Several pressure coefficients at the trailing edge show a high variation, indicated by the large error bars. Large fluctuations in the local pressures lead to a high variation of the $\frac{p_{M E M S, m}}{p_{d, N B, \text { cor }}}$ component in Eq. 2, causing this unsteady behavior. This is a sign for the beginning of flow separation.

The differences between the pressures on the upper and lower wing surface increase further, just shortly before the total collapse of flow conditions at the trailing edge. This condition is labeled with the No. 3 in the flight data plots. In the according pressure distribution diagram, the last seven MEMS pressure sensors show large error bars, a sign for a highly unsteady flow condition at the trailing edge. The point where the flow is detaching is clearly recognizable in a sharp increase of the error bar size of the MEMS pressure measurements.

Events No. 2 and 3 in Fig. 14 show also a significant divergence from the smooth progression in the mid-region
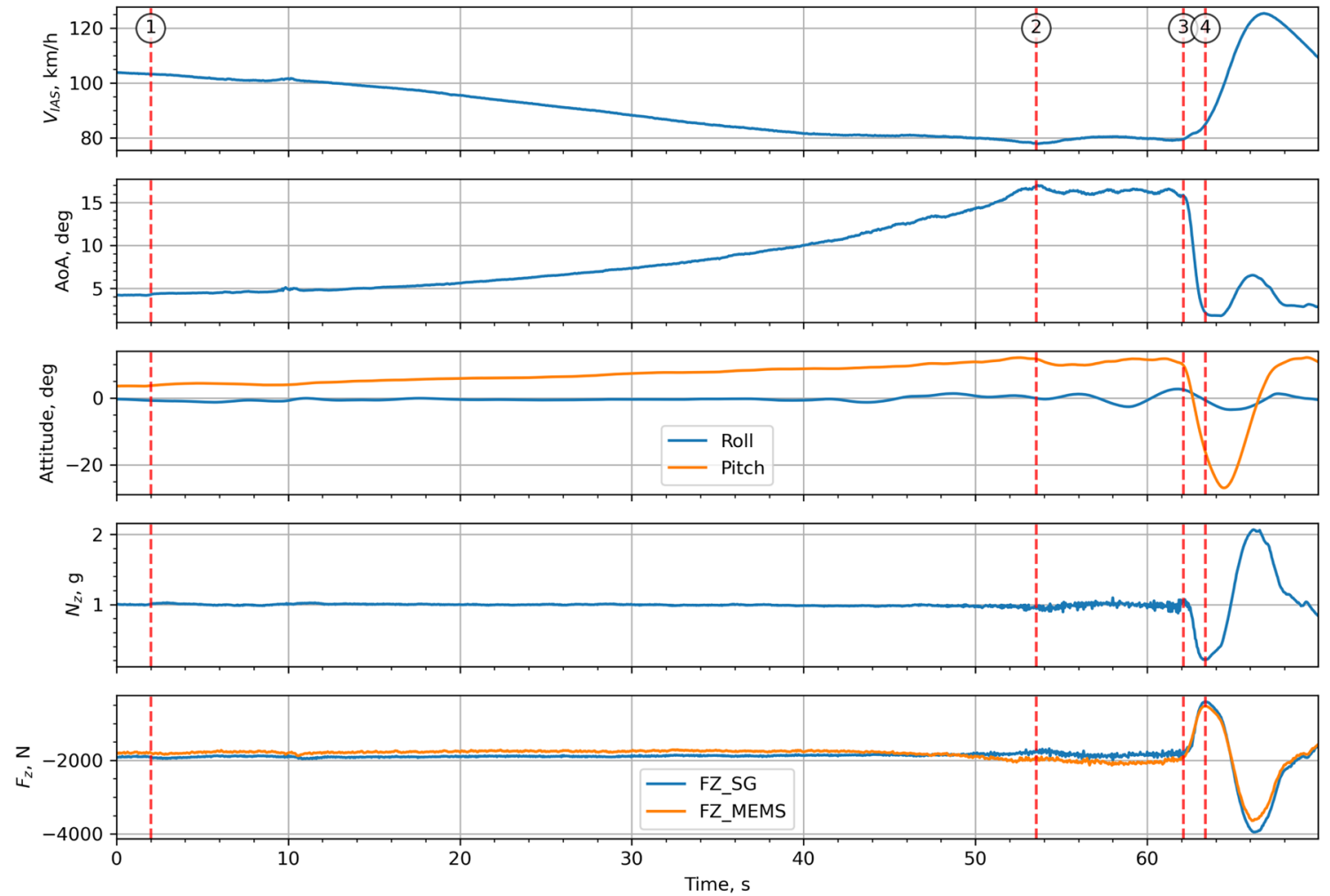

Fig. 13 Flight data measurements from a Stall flight maneuver 

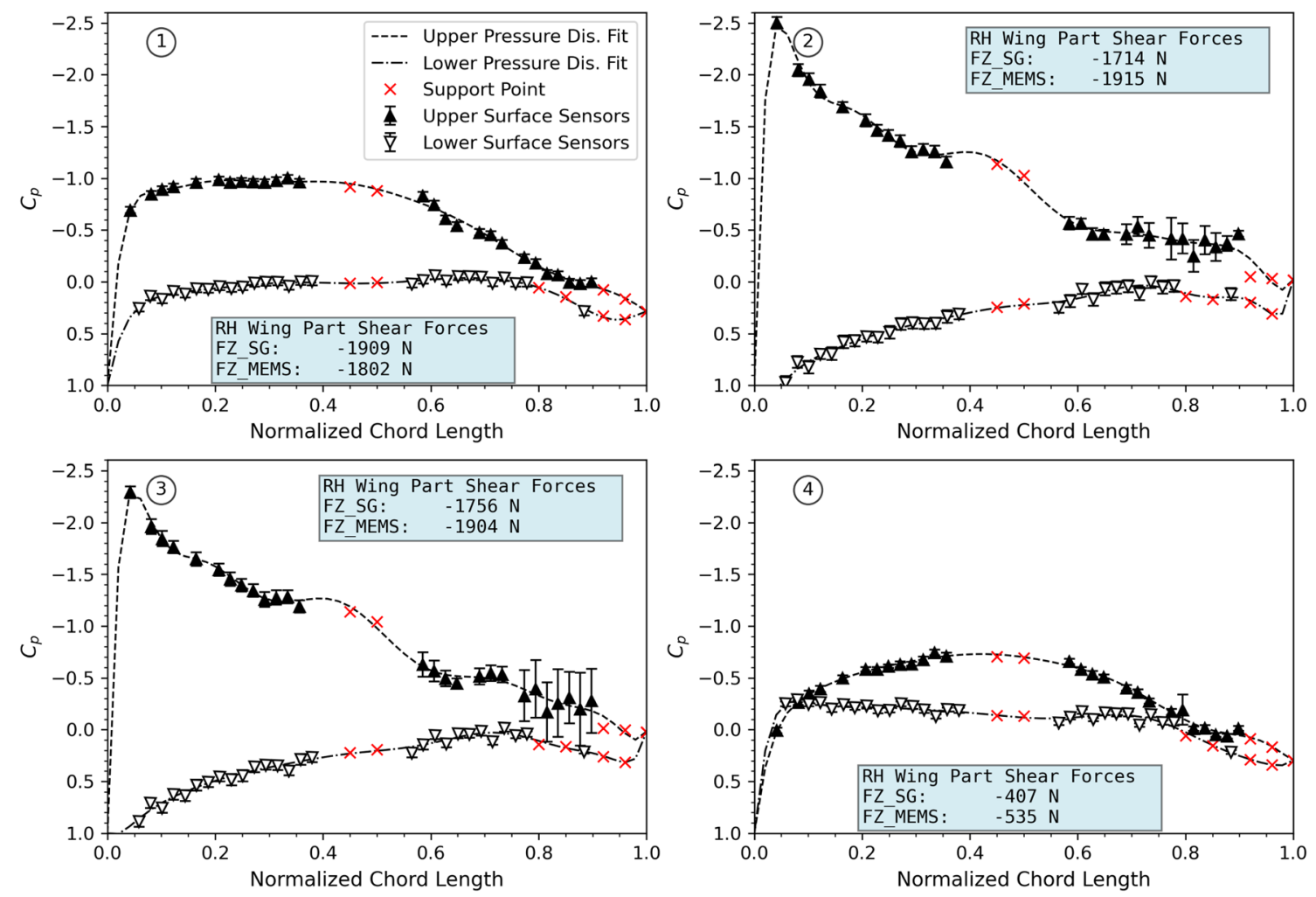

Fig. 14 Pressure distribution curves determined with MEMS pressure sensor measurements for specific points in time during the stall test maneuver

of the upper-pressure curve. This divergence results from a wrong interpolation of the supporting points, marked with the red crosses. As already mentioned these supporting points were calculated with an optimized XFOIL model. At high AoA however, this model tends to overestimate the pressure coefficients and does not represent the flow characteristics adequately for this flow condition. Installing more sensors in these affected wing parts would improve the pressure curve interpolation, because the supporting points could be replaced with real measurements.

Concerning the absolute shear forces determined for this condition, the one measured with the SGs is around $150 \mathrm{~N}$ smaller than the shear force determined with the MEMS sensors. One reason for this difference could be, that the local effects on the wing can not be captured with a single pressure belt on the inner wing. At high AoA's the outer wing has a different lift distribution due to different airfoil profiles and Reynolds numbers. Also the flow may start to separate at the outer parts of the wing, resulting in less local aerodynamic lift. This characteristic is measured by the SGs, but not by a single pressure belt, measuring only the local pressure distribution at one section of the inner wing. Another reason for the difference in the shear forces could be a wrong interpolation of the pressure distribution curves. This concerns especially the already mentioned supporting points in the mid-region of the upper wing profile.

At event No. 4, the vertical load factor reaches a value near zero. In the respective pressure distribution diagram the MEMS measurements show that the flow is again attached to the surface and has a similar characteristic like in the diagrams for the initial condition. The speed is increasing and the aircraft is recovered back to a horizontal flight condition.

\section{Conclusion and outlook}

The use of MEMS pressure sensors for the measurement of dynamic flight loads was investigated. Test maneuvers with dynamically changing aerodynamic loads were performed with the research glider aircraft Discus-2c. The aircraft was equipped with calibrated strain gauges, installed at dedicated load stations on the aircraft structure. A wing glove with 64 MEMS pressure sensors was designed for the measurement of the pressure distributions around the wing. The shear force on the RH wing was determined from the strain gauge measurements and the pressure distributions. Additional flight data was provided by an inertial reference platform and a 5-hole probe installed in front of the aircraft nose. The measured pressure distributions were evaluated 
for maneuvers with dynamically changing flight loads and a stall maneuver. A comparison of the shear force based on the strain gauge and based on the MEMS pressure sensor measurements was performed and analyzed.

The installed MEMS pressure sensors allow to examine the flow characteristic around the wing. They were able to measure the pressure distribution adequately, even in situations with unsteady dynamics. During the stall maneuver the MEMS pressure sensors were able to detect the point of flow separation. The in-flight detection of this point and its location on the wing airfoil play an important role for the evaluation of the overall aerodynamic performance. A better understanding of the local flow conditions could help to improve the design of critical structural components e.g. areas with flow interference or high aerodynamic loads.

Concerning the shear forces, the MEMS pressure sensor measurement method shows significant deviations during the dynamic load changes, especially in regions where $N_{z}<1.0$ and $N_{z}>2.0$. This deviation is attributed to the extrapolation of the wing glove pressure distribution along the total $\mathrm{RH}$ wing span. Wing flexibility and unsteady effects causing different local AoAs along the wing span were neglected with this experimental setup. The instrumentation of several wing sections with MEMS sensors will improve the measurement resolution on the wing. For a better determination of the pressure distribution around the airfoil it is also necessary to increase the number of sensors in the mid and trailing edge region. An improvement of the local resolution of the pressure measurements would make the calculation of support points obsolete.

It should be mentioned that the used measuring system is still an experimental prototype and the pressure distribution was only measured on a single wing cross-section. Differences between the calibrated strain gauges and the MEMS pressure sensors were, therefore, to be expected. Despite this simplified setup, the measured time histories of the shear forces, determined with both measurement methods, are not too far apart and show a good qualitative agreement. Besides the load determination, the MEMS pressure sensor technology has also the advantage to measure directly the aerodynamic characteristic of the structural component. Further research on the MEMS pressure sensors will concentrate on solutions for increasing the number of sensors in wing parts in the rear area of the wing and the design of pressure belts based on MEMS for the instrumentation of several wing sections. In the DLR project HighFly it is planned to perform flight tests with MEMS pressure sensors on the new DLR research aircraft Dassault Falcon 2000LX ISTAR. The performance of the MEMS sensors will be evaluated in higher altitudes and in the transonic speed range.

Acknowledgements The authors would like to thank the company messWERK GmbH Braunschweig for support with data acquisition and flight test instrumentation equipment. We especially would like to thank the colleagues and members of the DLR Department for Flight Experiments, the DLR Flying Group Braunschweig and the Akaflieg Braunschweig for flight test support and towing of the glider aircraft.

Funding Open Access funding enabled and organized by Projekt DEAL.

Open Access This article is licensed under a Creative Commons Attribution 4.0 International License, which permits use, sharing, adaptation, distribution and reproduction in any medium or format, as long as you give appropriate credit to the original author(s) and the source, provide a link to the Creative Commons licence, and indicate if changes were made. The images or other third party material in this article are included in the article's Creative Commons licence, unless indicated otherwise in a credit line to the material. If material is not included in the article's Creative Commons licence and your intended use is not permitted by statutory regulation or exceeds the permitted use, you will need to obtain permission directly from the copyright holder. To view a copy of this licence, visit http://creativecommons.org/licenses/by/4.0/.

\section{References}

1. Bosch Sensortec GmbH: Datasheet BMP280 Digital Pressure Sensor (2018). Rev. 1.19

2. Drela, M.: XFOIL: an analysis and design system for low Reynolds number airfoils. In: T. Mueller (ed.) Low Reynolds number aerodynamics : proceedings of the conference, Notre Dame, Indiana, USA, 5-7 June 1989, 54, pp. 1-12. Springer, Berlin (1989)

3. Eckstrom, C.V.: Flight loads measurements obtained from calibrated strain-gage bridges mounted externally on the skin of a low-aspect-ratio wing. NASA TN D-8349 (1976)

4. Goold, I.: Full circle the Boeing 787's troubled service entry and new engine technology have given the Airbus A330 a new lease of life. Aerospace Testing International, March 2018, edited by B. Sampson (2018)

5. Jategaonkar, R.V.: Flight vehicle system identification. American Institute of Aeronautics and Astronautics, Reston (2015). https:// doi.org/10.2514/4.866852

6. Jenkins, J.M., Kuhl, A.E., Carter, A.L.: Strain gauge calibration of a complex wing. J. Aircraft. 14(12), 1192-1196 (1977). https:// doi.org/10.2514/3.58914

7. Kottkamp, E., Wilhelm, H., Kohl, D.: Strain gauge measurements on aircraft. AGARDograph (160) (1976)

8. Lee, J.R., Ryu, C.Y., Koo, B.Y., Kang, S.G., Hong, C.S., Kim, C.G.: In-flight health monitoring of a subscale wing using a fiber bragg grating sensor system. Smart Mater. Struct. 12(1), 147-155 (2003). https://doi.org/10.1088/0964-1726/12/1/317

9. López-Higuera, J.M., Cobo, L.R., Incera, A.Q., Cobo, A.: Fiber optic sensors in structural health monitoring. J. Lightwave Technol. 29(4), 587-608 (2011). https://doi.org/10.1109/JLT.2011. 2106479

10. McCormick, B.W.: Aerodynamics, Aeronautics, and Flight Mechanic. Wiley, Amsterdam (1995)

11. Ostrower, J.: 787 first flight is just the start for gruelling programme. Flight Global (2009). https://www.flightglobal.com/ news/articles/787-first-flight-is-just-the-start-for-gruelling-pro336319/. Accessed 11th August 2020

12. Preisighe Viana, M.V.: Sensor calibration for calculation of loads on the DLR Discus-2c sailplane. DLR Technical Report 1112015/21 (2015) 
13. Raab, C., Rohde-Brandenburger, K.: In-flight testing of MEMS pressure sensors for flight loads determination. In: AIAA Scitech 2020 Forum (2020). https://doi.org/10.2514/6.2020-0512

14. Skopinski, T.H., Aiken, W.S.J., Huston, W.B.: Calibration of strain-gage installations in aircraft structures for the measurement of flight loads. NACA Report 1178 (1954)

15. Tanielian, M.H.: MEMS multi-sensor system for flight testing. Proc. SPIE Int. Soc. Opt. Eng. 4559, 120-129 (2001). https://doi. org/10.1117/12.443026

16. Tanielian, M.H., Kim, N.P.: Pressure belt: an integrated multisensor system. Proc. IEEE Sens. 1(2), 1182-1187 (2002)
17. Whitmore, S.A., Lindsey, W., Curry, R.E., Gilyard, G.B.: Experimental characterization of the effects of pneumatic tubing on unsteady pressure measurements. NASA Technical Memorandum 4171 (1990)

Publisher's Note Springer Nature remains neutral with regard to jurisdictional claims in published maps and institutional affiliations. 